\title{
Restoring Fort Frontenac in 3D: Effective Usage of 3D Technology for Heritage Visualization
}

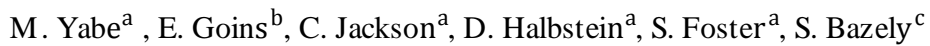 \\ ${ }^{\text {a }}$ Department of Visual Communication Design, Rochester Institute of Technology, Rochester, New York, USA \\ $<$ mxy 3663><cbjpgd $><$ scffaa $><$ dlhfaa $>@$ rit.edu, http://mxy3663.wix.com/fortfrontenac \\ ${ }^{\mathrm{b}}$ Department of Cultural Materials Science and Fine Arts, Rochester Institute of Technology, Rochester, New York, USA \\ esggsh@rit.edu \\ ${ }^{\mathrm{c}}$ Cataraqui Archaeological Research Foundation, Kingston, Ontario, Canada \\ sue@bazely.ca
}

Commission V, WG V/4

KEY WORDS : Heritage Visualization, 3D Computer Graphics, Interactive Virtual Design, Web Design, Effective Usage of Learning

\begin{abstract}
This paper is composed of three elements: 3D modeling, web design, and heritage visualization. The aim is to use computer graphics design to inform and create an interest in historical visualization by rebuilding Fort Frontenac using 3D modeling and interactive design. The final model will be integrated into an interactive website to learn more about the fort's historic importance. It is apparent that using computer graphics can save time and money when it comes to historical visualization. Visitors do not have to travel to the actual archaeological buildings. They can simply use the Web in their own home to learn about this information virtually. Meticulously following historical records to create a sophisticated restoration of archaeological buildings will draw viewers into visualizations, such as the historical world of Fort Frontenac. As a result, it allows the viewers to effectively understand the fort's social system, habits, and historical events.
\end{abstract}

\section{INTRODCUTION}

Fort Frontenac was an important military fortress and fur trading post that was built in Kingston, Ontario, Canada in 1673. Fort Frontenac was embroiled in occasional outbreaks of fighting between the Iroquois and the British, and was destroyed in 1689 but was then later reconstructed in 1695 to strengthen military activity and accommodation. Over the course of 50 years, fur trade gradually became more unprofitable, and the fort was relinquished to British forces during the Seven Year's War in 1758 who devastated it. The fort was never rebuilt, and was abandoned because the fortification was no longer needed. New buildings and streets were then erected above its ruins for more than a hundred years. In 1983, archaeological research finally successfully excavated only a small portion of the fort, the northwest bastion (Fig. 1). The fort was designated as a Canadian National Historic Site and a part of the northwest bastion was reconstructed in 1984 (Cataraqui Archaeological Research Foundation, 2013).

The aim of this paper is to virtually reconstruct all the buildings to look as they did originally. The field that embraces this process is called Heritage Visualization, which is derived from a combination of the use of conventional archaeology and cutting- edge 3D computer graphics design. The field has been used to recreate digital models from antiquity, such as ancient Egypt and Rome, at several research institutes around the world. It represents a great opportunity to rebuild Fort Frontenac using this technique because many forts have been renovated in this manner to show historical reenactment sites.

This research aims at virtually restoring an archaeological building, Fort Frontenac, which in turn will draw viewers into the historical world of Fort Frontenac. This is a difficult task because there is limited information and only a small amount of archaeological remains from the original Fort Frontenac. While the original maps and plans of Fort Frontenac are incomplete, a fertile imagination and computer graphics design skills are essential if the field is to help correct false assumptions regarding historical viewpoints. For example, what were the colors of the buildings? Color may be involved with an overly subjective viewpoint. What were its social system, habits, and historical events at that time? Application of this field will also allow viewers to effectively understand the fort's social system and historical events. The target audience is those who are interested in history and archaeology. For those who are not able to visit Fort Frontenac because it is too far away from their residence, this thesis is designed to expand their knowledge, while saving 
money and time. Historical Visualization is a vital field by means of Internet access to view not only the fort, but also many other forts as well as other historic buildings and their architectural features, such as castles, all over the world. The method used in this process is important to disseminate in this paper for educational and economic purposes.

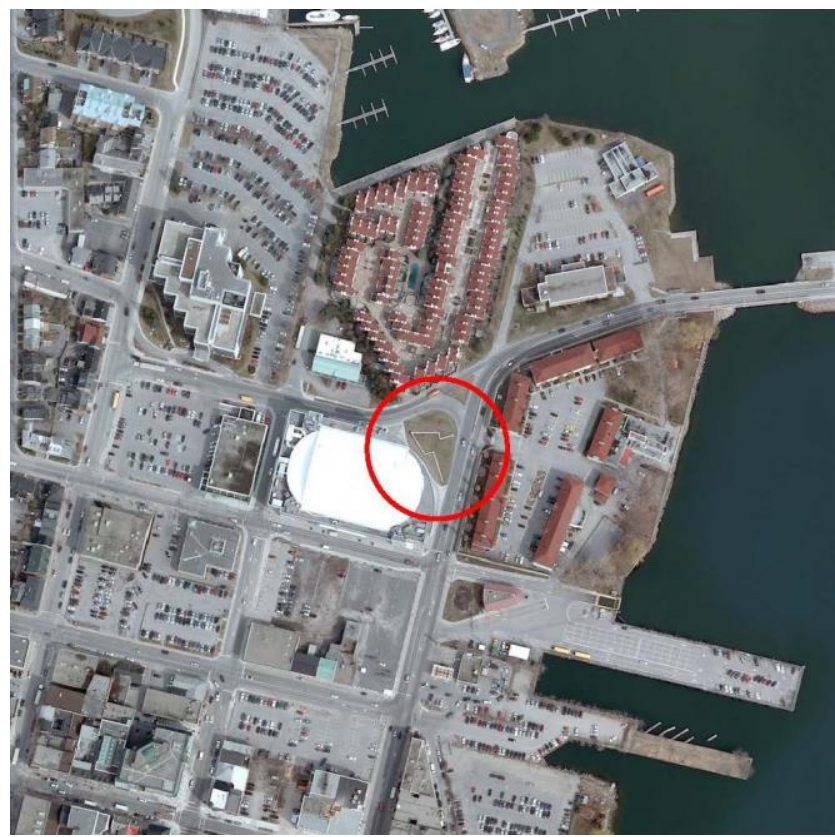

Figure 1. Aerial imagery of surroundings around the remnants of Fort Frontenac @ The City of Kingston Copyright 2011.

\section{PROCESS}

\subsection{Design Approach}

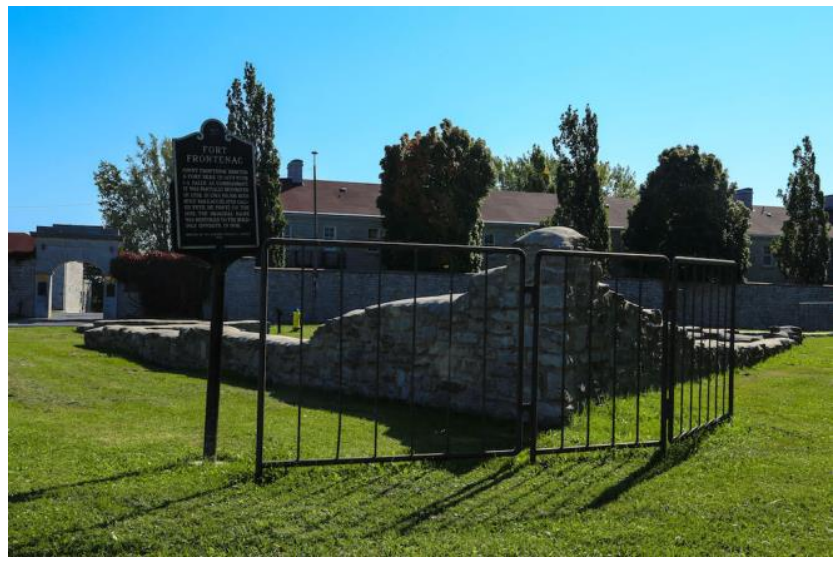

Figure 2. The remnants of Fort Frontenac.

First, in order to approach a true picture of Fort Frontenac and its surroundings as they existed in the past, meticulous research was required via historical maps, plans, and architectural styles of the fort at that time using the Internet and libraries. Print and online documentation, such as books, are good resources for this process. However, a physical visit and an archeologist's opinion are more advantageous to developing exceptional research. The dates that this researcher visited Kingston, Canada, were on December $3^{\text {rd }}$, 2013 and on September $26^{\text {th }}, 2014$ (Fig. 2) in order to photograph and glean information about the target fort. Furthermore, a consultation with a local archaeologist, Mrs. Susan Bazely, was well worth sharing her knowledge, experience in archaeological research, and insights for research development. Envisioning the fort's restoration was taken advantage of by filtering the collected information and photographs and then sketching out designs on paper. A good guide for the 3D modeling using Maya software was to set up to scan drawings and blueprints.

After the design research was completed, the following practical software was essential to building models: Adobe Photoshop, CrazyBumps, and Autodesk Maya. An initial plan was to model the interior of the buildings, but that plan was cancelled because research was lacking for credible information regarding the $17^{\text {th }}$ century. The exterior of the fortress was constructed in five steps, including the following years: 1673, 1675, 1680, 1685, and 1688. The 3D modeling techniques used included polygon modeling, shading, and lighting. The textures of the building were shaded, and the background of the building and its surrounding environment were added by lighting adjustment. The completed models were rendered to produce video clips and interactive animations through camera movement, which set in motion as a $3 \mathrm{D}$ camera was placed to create a bird's eye-view and a 360degree view from the fort.

After the modeling was complete, interactive sceneries in Adobe Flash were devised to provide an effective way to implement visual communication and learning through the use of a mouse. The interactivity was integrated into the 3D models of the fort with unseen clickable buttons in order to allow the viewer to learn more about the fort's structure and historical importance. The video clips and interactive sceneries were integrated into the website in order to inform the user of the fort's social systems and historical events. Also, the purpose for this is that people prefer to stay at home without visiting a location that is far from their residence, so the uploaded website's goal is to excite the user's curiosity about the fort.

\subsection{Modeling Buildings in Maya}

2.21 Constructing Buildings and Environment: Maya 2014 is a professional tool that has the means of modeling physical objects and rendering sequences to create animations. By complying with the notes regarding the archaeological and historical consequences of the research, such as photos taken during the visit to the forts, online documentation, and historical plans and print documentation provided by the City of Kingston, as well as Mrs. Bazely's evidence ${ }^{1}$, and the extremely restricted

\footnotetext{
1 Bazely, Susan M., email message to Mitsuy oshi Yabe, February 26, 2014.
} 
information about Fort Frontenac in the $17^{\text {th }}$ century that was available, the archaeological features of the building construction and their exteriors were required to be meticulously elaborated. The careful operation was performed in Maya in order to fashion the length, height, and size of each building, including the log palisades, curtain walls, and moats.

In addition, Crazybumps is a convenient software program for shading textural materials where photos were simultaneously turned into displacement and normal maps. The software is the most effective, simple and easiest way of creating these types of maps, since the software is beneficial to the enhancement of aesthetics and contrast. Four, six, or eight images became two or four of each image by means of flipping the images vertically and horizontally and then stitching the original whole images together with much repetition in Photoshop. The images were offset, and the clone tool was used to make seamless repeating patterns (Fig. 3). The more images that were put on the one large image in Photoshop, the more realistic the textures of the buildings were when the images were transformed to displacement and normal maps adjusted by Crazybumps according to intensity sharpen, detail, shade, and highlight, which were then imported into Maya. Finally, the normal maps were placed along with the displacement maps onto a Blinn bump map for particular buildings. Most texture images were provided by a website referenced as Cgtextures, which has abundant and wide resources of textures that range from ancient to modern.

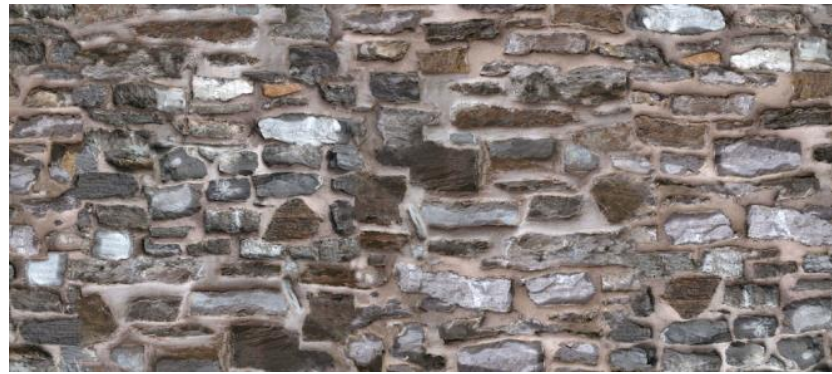

Figure 3: A classic sample of stitched textures for the fort's curtain wall done in Photoshop.

For the 1673 imagery, the constructed buildings included the following: two storehouses for provisions and ammunitions storage, log palisades whose north and south sides were forty-six feet and the other sides which were twenty feet in length, and a well (Stewart, 1982). For the restoration of the wooden palisades, as a sequel to researching their detailed textures among old forts in America that were built in the $17^{\text {th }}$ century, their average colors were shabby, drab, and gray with a few knots which could possibly be attributed to a kind of oak, beech, or cedar. For the 1675 imagery, the log palisades had the addition of four limestone square bastions in an area that was 800 yards in circumference (Stewart, 1982). The masonry textures of the bastions were originally made from remnants of Fort Frontenac because Mrs. Bazely mentioned that the surfaces appeared to be yellowish, rough, and blunt ${ }^{2}$. For the 1680 imagery, the constructed buildings included the following: a one-hundredfoot-long quarters, a blacksmith shop, a guardhouse, a cow house, a well, wooden platforms and scaffolds and log palisades on the North, East, and South sides, as well as masonry curtain walls on the West side, with the addition of four limestone square bastions. Around the fort were 15-foot-wide ditches (Stewart, 1982). The masonry curtain walls included many casements and loopholes, and it took a lot of time to meticulously embed the casements and loopholes within the wall (Stewart, 1982). For the 1685 imagery, the fort was enlarged in a square alongside each of four bastions, which measured approximately 96 feet from curtain wall to curtain wall. The South Side had a combination of a 4-foot-high masonry foundation wall and log palisade that stood on the foundation wall. The inside included a masonry quarters or barracks, a guardhouse, a forge, mills, a powder magazine, a bakery, trade house, a well, a sentry-box, and moats that were fifteen feet deep (Stewart, 1982). For the 1688 imagery, the additionally constructed buildings included the following: a large tower and four small towers, wooden platforms and scaffolds, a wooden bridge, a masonry gate, and full limestone curtain walls with many casements and loopholes (Stewart, 1982). The flag with the pole on the big tower was also added. Most of buildings were completely transformed from wooden surfaces to limestone surfaces. However, some buildings still remained with wooden textures. Both textures were replaced because the fort had to be strongly reinforced due to the improvement of the military services and the interior exploration.

The log textures were from $\mathrm{Cgtexture}$, and the limestone textures were from the remnants of Fort Frontenac. The six similar, repeated images were stitched together using offset in Photoshop in order to respectively adjust the surfaces of each pole on the UV texture editor in Maya. For the roofs and wooden walls of the two storehouses, the textures were also found in Cgtexture, and were created by the same means of Photoshop and Crazybumps with the results being placed onto bump maps using Maya. Textures were then put on each building by following these methods (Figs. 4 - 6).

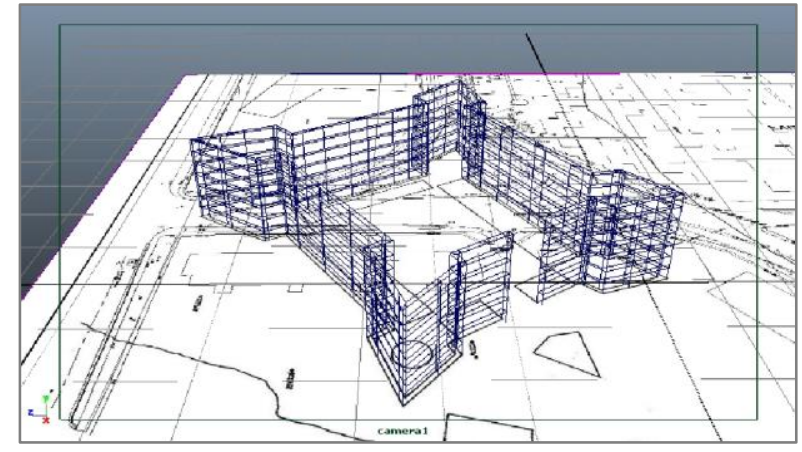

Figure 4: The wireframe model of the 1688 fortress.

2 Bazely, Susan M., email message to Mitsuy oshi Yabe, February 26, 2014. 


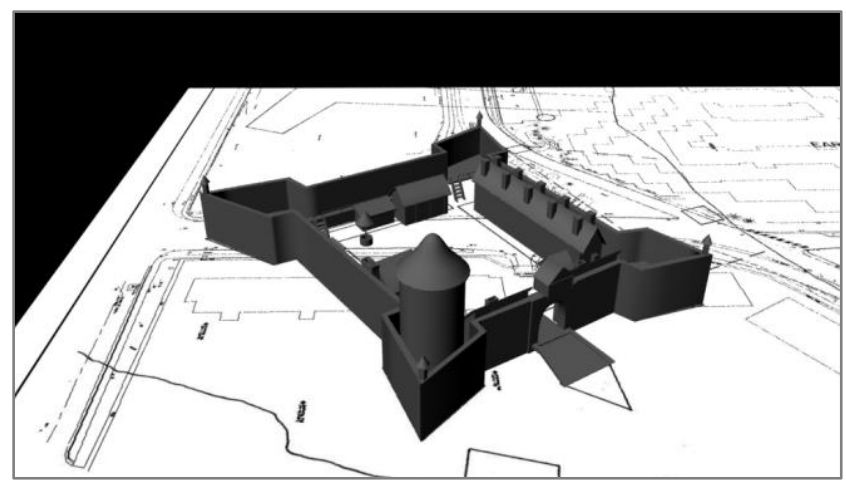

Figure 5: The wireframe model of the 1688 fortress.

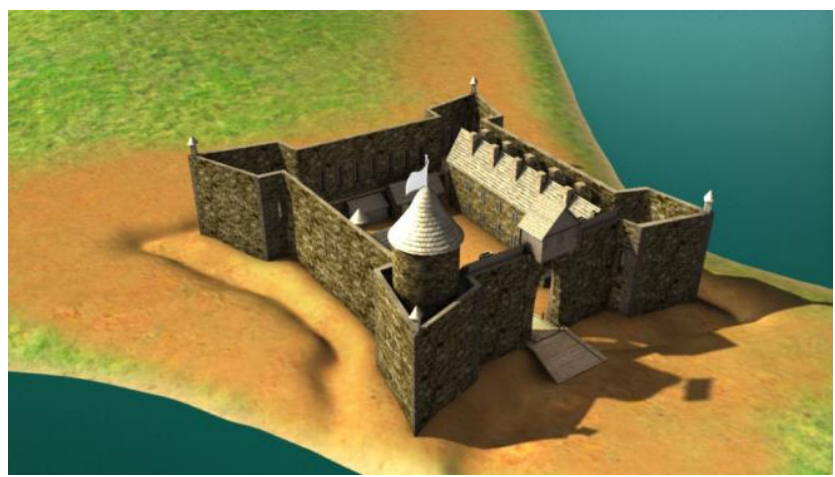

Figure 6: The wireframe model of the 1688 fortress.

Geographic landscapes were created in May a by means of tracing curves over the outline of the plans for $1685^{3}$ which were provided by the City of Kingston. The outline became a planar surface and that surface was converted into a polygon surface with numerous quarter geometries. As the ensuing landscapes for $1673,1675,1680,1685$, and 1688 , were created, the geometric maps were shot by the UV Snapshot included in the UV texture editor in Maya and were imported into Photoshop to create color geographic topography. A displacement map and a normal map were created in Crazybumps and were then imported back into Maya to be placed onto a bump map for the landscapes. Moreover, the sea was created by means of using an Ocean Shader and Ocean, and minor corrections were required until the color was very similar to the color of the sea around Kingston that was dully emerald or bluish in color.

Three lights were also set up: Key Light, Fill Light, and Back Light. The key light was like sunlight set as a directional light, turned towards the north, and its color was slightly bright yellowish. The Fill Light was a secondary light set as a spot light facing southwestward, and its color was slightly bluish. The Back Light was the third light set as an additional spot light in a southern direction, and its color was dimly warm orange. Originally, the fort's gate was turned northeast so that the

3 Fort Frontenac Based on A 1685 Map. Map. Scale 1:1000. Kingston, Ontario: City of Kingston, 2006. entrance was in shadow in the northeastern direction. The three lights were crucial materials used to heighten an aesthetic sense of natural imagery. In order to create the dynamic moving sky, the sky image was distorted using polar coordinators in Photoshop and the hemisphere modeling was mapped with the image onto the UV texture editor under spherical mapping to eliminate seams in the top sky. The hemisphere modeling was placed so as to entirely hide the forts and geographical landscapes. It was designed for use as a camera application to further an appreciation of the area's natural aesthetics. Lastly, in order to make shadows look realistic, ambient occlusion (AO) can be used to help soften and deepen shadows and to refine a clearly visible separation between objects in a totally white scene. This technique can create a more realistic AO rendering (Fig. 7).

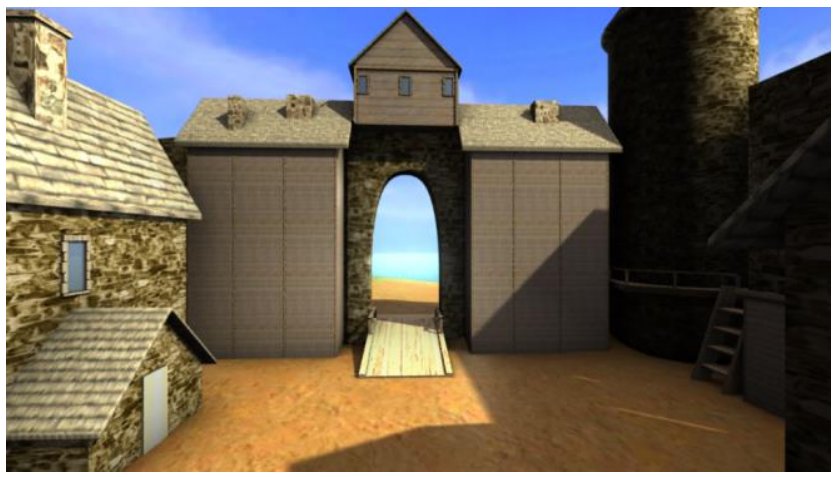

Figure 7. The restoration of the entrance of Fort Frontenac in 3D computer graphics.

\subsection{Rendering Sequences to Create Videos and Interactive} Design: Regarding the camera animation, rendering PNG sequences featured an overview of the forts for a series of all construction dates and inside views of the forts for 1675, 1680, 1685 , and 1688, as well as providing ambient occlusion renderings for all those scenes in video clips. The 1673 version was not included because the inside was too narrow to create a video. A "Two Node" camera was set as the camera body and an aim constraint. This allows the camera to focus on one object while the body is moved. Different circular curves were created to become a motion path attached to each camera in order to make the cameras move very smoothly. Nine hundred frames were required for an overview of the exterior of the 1688 fort and ambient occlusion renderings for the fort in sequence. It took an average of six to nine hours to get this smooth for the videos.

Both of the completed sequences were imported into Adobe After Effects software and then placed as AO sequences under the "multiple" color sequences setting in order to be semitransparent, making the sceneries appear more realistic, and then rendered for videos. The preferable time length for the videos was twenty-four seconds for an overview of the exterior. These setups were needed to make viewers visually comfortable according to the motion and timing.

Two videos were set as a chronological series of the two kinds of entire exteriors of the forts. The images for each were simply 
taken from Maya, which was a simple and easy way to ensure that each image was ordered chronologically and the corresponding chronological date texts were aesthetically put on each of the images in After Effects. For the aspect of interactive design, only thirty-six frames were required to render an overview of the exterior and interior of the forts, including ambient occlusion renderings for both. It took thirty minutes to set all the frames and install the historical sequences respectively for $1673,1675,1680,1685$, and 1688 .

\subsection{Creating Interactive Imagery in Flash}

Flash CC is reliable software designed to play a major role in interactivity. An SWF format generated from Flash was designed for the interactive application for this project and was equipped to become integrated with the website. From a technical view, the interactive animation was set up to play at a rate of only thirty-six frames. The coding was typed and fixed on the action scripts in order to fit the interactive scenery (Fig. 8). The names and descriptions of each building were placed in panels. The descriptions were integrated from the research result derived from trustworthy online and print documentation. These panels were placed around each building using transparent black color with high opacity, and Palatino Linotype was used as the font in white text on the basis of its visual effect. Once the SWFs were published, the interactive system enabled users to hover over a certain building with a mouse where the panels including its name and description popped out (Fig. 9). This application could help to explore users' comfort, the effective application of learning about the fort through interactivity, and animation principles. This idea will be a useful educational tool to let users learn about the fort's historical importance and to acquire new knowledge, as well as assisting in the development of educational and study materials.

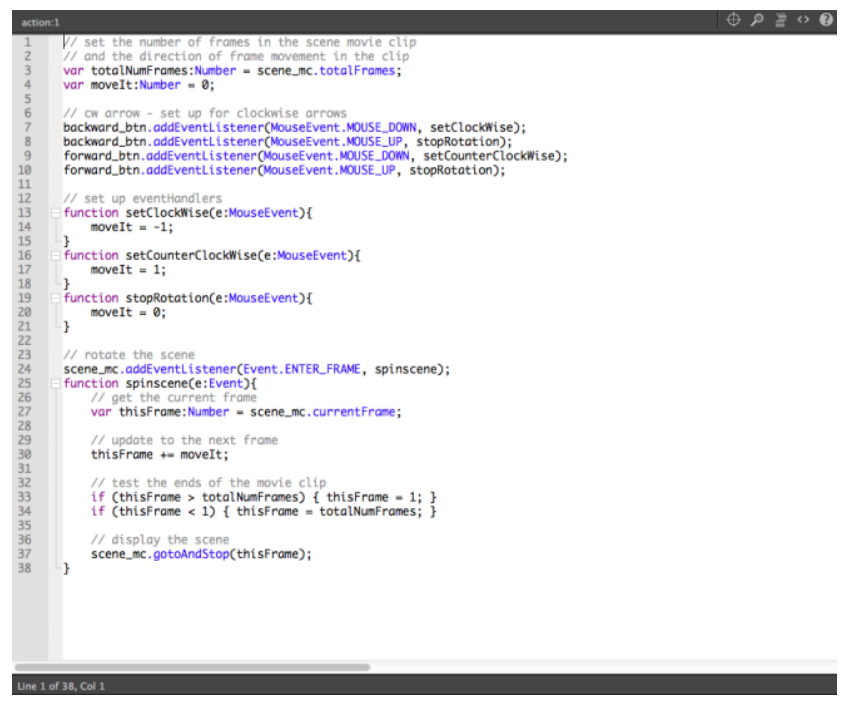

Figure 8: Codes in action scripts.

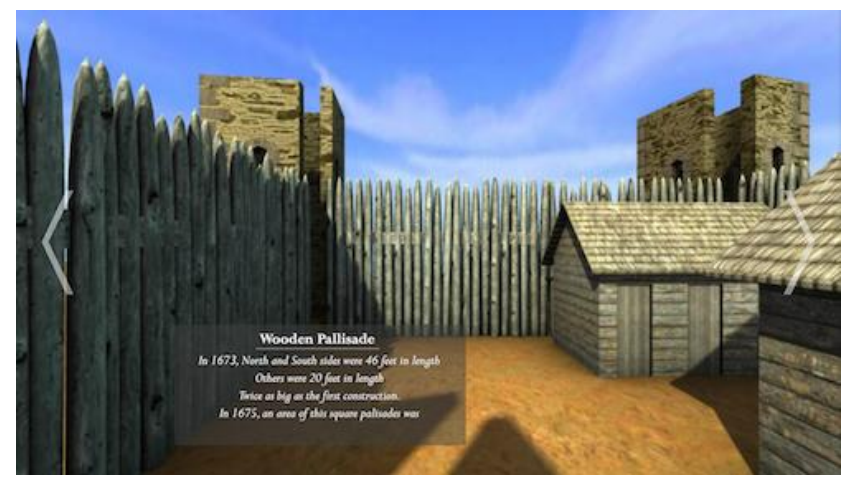

Figure 9: The interactive scenery of the 1675 interior fortress.

\subsection{Designing the Website}

Wix, as a website hosting and design tool, provided indispensable web assistance, which is helpful to a beginner in designing attractive websites without coding within a short time frame. Wix is able to convey information more effectively within a limited time than multimedia. Even so, it took a lot of time for a novice to design a website that included numerous entangled codes. In terms of layout design, the color of the top bar was a slight crimson, and the main background was slightly yellowish beige or grey with high opacity under the old map. The reason for the color choices were that the outline and background of the old fort's map plan had colors in common with the roof and wall of the National Defence College that were built on the front of the fort's remnants. The classic font Palatino Linotype was chosen again in order to appear similar to old, traditional French fonts. The site reanimates time reenactments of French settlements in Canada (Figs. 10 and 11).

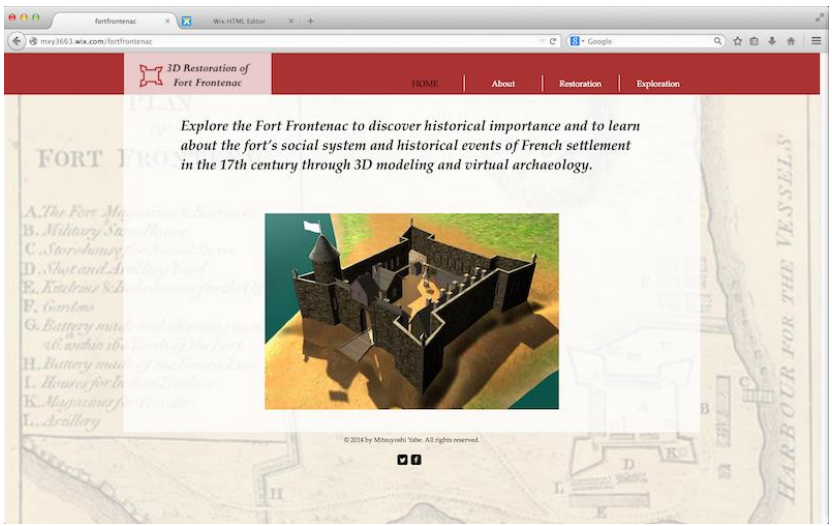

Figure 10: The website of the 3D restoration of Fort Frontenac.

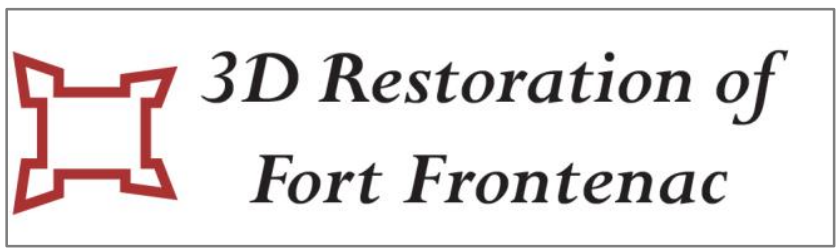

Figure 11: A sample of the representative logo. 


\subsection{Critical Analysis and Troubleshooting}

In fact, there were several issues that occurred during this research. Each struggle greatly affected the process of how the research and project was critiqued and improved. The following is a critical analysis and troubleshooting of what went right and/or wrong and how to solve the issues.

The first plan was to create three kinds of videos: an outside overview of the forts, an inside overview of the forts, and a closeup of the gate for each of the years: 1673, 1675, and 1688. Nine hundred frames were essentially required to produce a 36 -second video for the outside overview, six hundred frames to produce a 24-second video for the inside overview, and three hundred sixty frames to produce a 12-second video for the close-up of the gate. Rendering nine hundred frames greatly impacted the researcher's lifestyle on a daily basis. It took one day to complete one video. To create the full set of nine videos required a week. On the other hand, to create interactive sceneries for the outside and inside of the forts in Flash CC took only 30 minutes to render all twenty four frames necessary to build a 360-degree interaction in Flash. At that rate, more than 10 interactions could be created on a day. However, designing a related website was influenced by the video file formats and interactive sceneries for each page. Usercentered design determined the best method to incorporate the videos. Consequently, most videos were removed due to their memory-intensive usage and the time management required. Only the videos for the completed exterior fort in 1688 were uploaded for the webpage. The website featured nine interactive sceneries: the interiors for $1673,1675,1680,1685$, and 1688 as well as their exteriors respectively, except for 1673. The appearance of the website was innovative and comfortable for users to deal with and enhanced their knowledge in an effective way. In comparison, watching the videos was not innovative and banal. To sum up, this design could assert that interactive applications are attractive to users and usefully economize the time spent creating them, but featuring videos is relatively conventional and expends considerable effort and time.

\section{CONCLUSIONS}

Modeling buildings and the related environment created a lot of challenges and many difficulties because there was very little information available about the $17^{\text {th }}$-century Fort Frontenac. Further information was needed to clarify that Fort Frontenac was compared with other forts that were relatively similar to the target fort, according to their various sizes, such as the height, length, and width of buildings as well as the textures of the buildings and the environment surrounding them. To make the visual motion smooth and slow, nine hundred frames in the rendering sequences were required to create the video clips. Needless to say, the average rendering time was nine hours, and occasionally several defections from the rendering occurred, so the constant supervision was important to the rendering a few times each hour.

The successful website can be made available to public; however, for the past few years there have been further issues with some functions that depend on the consistently upgraded versions of several software programs, such as Flash. In a few years after the website is published, the website may not be useful due to the expiration of a version of a certain software that may not match a particular browser, or a computer that requires a newer version. This would require upgrading to new versions determined by users' needs. In addition, annually hosting the website may prove too costly as well.

Nevertheless, the achievement of a 3D virtual model and an interactive website will enable users to effectively learn about the historical importance of Fort Frontenac. In addition, users can quickly view its exterior from various different perspectives. The development of an interactive website is essential to, and entirely prevalent in, the current world through the development of a many-sided website that enhances digital visualization. The aim was to take the content and make it a more beneficial experience through the use of a vivid video screen rather than by merely studying textbooks. This technique also encourages users to understand the fort's social system and the historical events that occurred at that time of the fort's operation.

By changing the consumer's understanding to an archaeological viewpoint, the field continues to evolve step-by-step. 3D techniques and web design gradually supports this evolution, even though the technology is still developing in areas such as comfort and convenience for modeling, importing colors and sounds, lighting, shading, setting items in motion in $3 \mathrm{D}$, visually communicating a 3D screen, and interactively using a mouse in a website. The more the technology improves, the more heritage visualization can develop. Historical sites which are in repair and abolished cultural methods can be resuscitated and examined through the use of the latest technology.

\section{ACKNOWLEDGEMENT}

The author would like to thank Dr. Elizabeth Goins, Mr. Chris Jackson, Mr. David Halbstein, Mr. Shaun Foster, and Mrs. Susan Bazely for giving useful advice on this research work.

\section{REFERENCES}

Bazely, Susan M., Jonas Fernandez, and Helen Sheldon. Archaeological Assessment Place D'Armes Re-Alignment Kingston, Ontario. Kingston, Ontario: Cataraqui Archaeological Research Foundation, 2007.

Bazely, Susan M., email message to Mitsuy oshi Yabe, February 26, 2014. 
Canada's historic Place, s.v. "Fort Frontenac National Historic Site of Canada" accessed September 10, 2013, http://www.historicplaces.ca/en/rep-reg/placelieu.aspx?id=12130

Cataraqui Archaeological Research foundation, s.v. "Fort Frontenc," accessed September 10, 2013, http://www.carf.info/kingston-past/fort-frontenac

Fort Frontenac Based on A 1685 Map. Map. Scale 1:1000. Kingston, Ontario: City of Kingston, 2006.

Frischer, Bernard. "Rome Reborn." Last modified August 1, 2013. http://romereborn.frischerconsulting.com

Preston, Richard Arthur. Royal Fort Frontenac. Toronto: The Champlain Society, 1958.

Stewart, Bruce W. The Kingston Harbourfront Archaeological Project Phase II, Fort Frontenac: Results of the 1982 Test Excavations. Kingston, Ontario: Cataraqui Archaeological Research Foundation, 1982. 